\title{
Laparoscopic transabdominal cerclage: Outcomes of 121 pregnancies
}

\author{
Dr Alex Ades; MBBS, MD, PhD, FRANZCOG ${ }^{1}$ \\ alex@ades.com.au
}

Dr Sneha Parghi; MBBS, MRANZCOG ${ }^{2}$ (Corresponding Author)

sneha.parghi@agoracentre.com.au

Dr Mehrnoosh Aref-Adib; MBBS, MA, MRCOG ${ }^{2}$

Mez.aref@yahoo.co.uk

\section{University of Melbourne}

Department of Obstetrics and Gynaecology

Royal Women's Hospital, Melbourne

Victoria, Australia

2. Agora Centre for Women's Health

Epworth HealthCare Richmond

89 Bridge Rd, Richmond

Victoria, Australia 3121

Ph: (03) 94212533

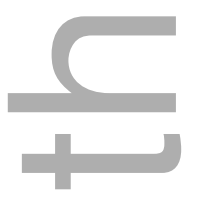

Conflicts of Interest: None

\section{Acknowledgements}

Dr Kim Dobromilsky, Dr James May, Dr Phoebe Hong

This is the author manuscript accepted for publication and has undergone full peer review but has not been through the copyediting, typesetting, pagination and proofreading process, which may lead to differences between this version and the Version of Record. Please cite this article as doi: $10.1111 / \mathrm{AJ} 0.12774$

This article is protected by copyright. All rights reserved 
DR. SNEHA PARGHI (Orcid ID : 0000-0001-6406-8782)

Article type : Original Manuscript

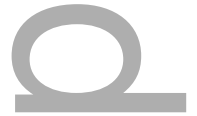

\section{Laparoscopic transabdominal cerclage:}

\section{Outcomes of 121 pregnancies}

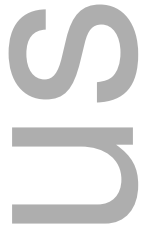

Conflicts of Interest: None

Word count:

Abstract: $\quad 215$

Main text: 2499

Table count: 4

Key words: cerclage, laparoscopy, premature, preterm birth, cervical insufficiency.

Abstract

Background: Cervical insufficiency is a significant cause of morbidity and mortality. Cervical cerclage is one option in the management of cervical insufficiency.

Aim: To evaluate obstetric outcomes following insertion of a pre-pregnancy laparoscopic transabdominal cerclage in women at high risk for pre-term labour and/or mid trimester pregnancy loss.

Methods: A prospective observational study of consecutive women who underwent laparoscopic transabdominal cerclage from 2007 to 2017. Eligible women had a diagnosis of cervical insufficiency based on previous obstetric history and/or a short or absent cervix and 
were considered not suitable for a transvaginal cerclage. The primary outcome was neonatal survival and the secondary outcome was delivery of an infant at $\geq 34$ weeks gestation. Surgical morbidity and complications were also evaluated.

Results: 225 women underwent laparoscopic transabdominal cerclage during the study period. We present the outcomes of 121 pregnancies resulting in 125 babies. The perinatal survival rate of viable pregnancies was $98.5 \%$ with a mean gestational age at delivery of 35.2 weeks. $79.7 \%$ of babies were delivered at $\geq 34.0$ weeks gestation.

Conclusion: Laparoscopic transabdominal cerclage is a safe and effective procedure resulting in favourable obstetric outcomes in women with a poor obstetric history. For optimum success the procedure requires the correct surgical expertise, equipment and appropriate patient selection.

Keywords: cerclage, laparoscopy, premature, preterm birth, cervical insufficiency.

\section{Introduction}

Every year, an estimated 15 million babies are born preterm ${ }^{1}$. One cause for preterm birth or fetal loss is cervical insufficiency. Classical cervical insufficiency is a retrospective diagnosis, based on an obstetric history of recurrent second- or early third-trimester fetal loss, following painless cervical dilatation, prolapse or rupture of the membranes, with expulsion of a live fetus despite minimal uterine activity ${ }^{2}$.

The reported incidence of diagnosed cervical insufficiency is between 0.1 and $1 \%^{3}$ with variation in the incidence as a result of difficulties in diagnosis and data collection ${ }^{4}$. One definition includes women with a prior preterm birth and evidence of cervical shortening $(<25 \mathrm{~mm})$ on transvaginal ultrasound, increasing the incidence to $3-4 \%$.

Currently no objective test can confidently identify women with cervical insufficiency in the non-pregnant state- In 1955, Shirodkar reported successful treatment of cervical insufficiency by using a transvaginal approach to place a purse-string catgut suture at the level of the internal os in women with recurrent midtrimester pregnancy loss ${ }^{6}$. MacDonald ${ }^{7}$ modified this technique and this is the most commonly performed cerclage technique ${ }^{8}$.

A transabdominal cerclage (TAC) is an alternative approach for women in whom a TVC has failed, or is not possible due to an extremely short or deformed cervix, such as after trachelectomy. The advantages of TAC include: the ability to place the cerclage suture higher up at the level of the cervico-isthmic junction; avoiding a foreign body inside the vagina, 
reducing bacterial colonisation that can lead to infection and preterm labour; and the ability to leave the suture in place for eventual future pregnancies.

Transabdominal placement of the cerclage was first described by Benson in 1965 as an open procedure, which carries a risk of considerable morbidity for the mother and the foetus. Lesser et al first described laparoscopic TAC in $1998^{9}$. Since then, further case reports and small series have been published, demonstrating equivalent obstetric outcomes to open TAC, but with a reduction in hospital length of stay, post-operative pain and blood loss ${ }^{10,11,12}$.The aim of this study is to review the obstetric and surgical outcomes of the largest case series of pregnancies with laparoscopic TACs to date.

\section{Materials and Methods}

We conducted a prospective observational study in a consecutive series of women who underwent a pre-pregnancy laparoscopic TAC between August 2007 and March 2017. Eligible women with a history suggestive, or evidence of cervical insufficiency, requiring a cervical cerclage and who were considered not suitable for a TVC were included. Women who were pregnant at the time of the transabdominal cerclage were excluded.

Referrals were received from the Royal Women's Hospital in Melbourne and other Australian hospitals. Following insertion of the laparoscopic TAC, women returned to their obstetrician.

\section{Indications for insertion of laparoscopic TAC}

Indications for a TAC were either one or a combination of the following: previous failed TVC, previous suboptimal TVC, absent or very short cervix after surgery, patient request after one or more midtrimester losses or extreme prematurity with a history of cervical insufficiency. Failed TVC was defined as a pregnancy loss despite insertion of a TVC. Suboptimal TVC was defined when the pregnancy resulted in a live birth, but at a high personal cost - prolonged hospitalisation and bed rest during pregnancy and/or admission of

the baby to the neonatal intensive care ${ }^{11}$. A short cervix was defined as being less than $25 \mathrm{~mm}$ on scan or on clinical examination.

\section{Operating surgeon}

All cerclages were done by a single surgeon (AA) in Melbourne, Australia. The laparoscopies were performed under general anaesthesia according to standard surgical protocol.

Technique used

We use a modification of the surgical technique described by Whittle et $\mathrm{al}^{13}$. The procedure is performed through four port $\mathrm{CO}_{2}$ operative laparoscopy. An incision is made to the visceral peritoneum at the level of the utero-vesical fold and extended laterally to the broad ligaments. 
The para-vesical spaces and then the utero-vesical space are dissected and the bladder is reflected away from the cervix. After identification of the ureters and uterine arteries, windows are opened on the broad ligaments providing full exposure of the cervix and ascending branches of the uterine vessels. A 1 Prolene $^{\mathrm{TM}}$ (Ethicon Inc., Somerville, NJ, USA) suture is then passed twice at the level of the uterine isthmus medial to the uterine vessels to create a double loop with the knot tied at the back. The surgeon's choice for suture is Prolene as it is a mono-filament non-braided suture, with minimal tissue reactivity and proven durability.

$\underline{\text { Outcomes }}$

Primary outcome was neonatal survival. This was defined as survival 30 days after discharge from hospital. Secondary outcome was delivery of an infant $>34.0$ weeks gestation. We also reviewed surgical morbidity and complications.

\section{$\underline{\text { Ethics }}$}

Ethics approval was obtained from the Royal Women's Hospital, Melbourne, Research Committee and Royal Women's Hospital, Melbourne, Human Research Ethics Committee.

$\underline{\text { Data collection }}$

Patient demographics, medical, surgical, obstetric and gynaecological history and indication for cerclage were recorded. Perioperative data included duration of procedure, time in hospital, blood loss, analgesia requirement and surgical complications. Obstetric outcomes were collected directly from obstetricians providing care, hospital charts and telephone interviews with patients.

\section{Results}

Over 10 years, a total of 225 women underwent insertion of laparoscopic TACs. The mean age at insertion was 33.9 years (+/- 4.39 years). After the procedure, 193 patients $(86 \%)$ were discharged on the same day and 32 remained in hospital overnight. $97 \%$ of patients left the hospital in less than 24 hours.

No cases were converted to laparotomy. The average procedure time was 60.6 minutes which included the additional procedures such as treatment of endometriosis, adhesiolysis, myomectomy and hysteroscopy. Patients were not given intraoperative antibiotics routinely. The overall complication rate was $1.3 \%$. There was one post-operative wound infection, treated with antibiotics. There was one intra-operative bladder injury that was sutured laparoscopically. There was one uterine fundal perforation sutured laparoscopically. In two cases, the cerclage was not performed. One patient had extensive endometriosis with rectal 
disease causing obliteration of the pouch of Douglas and and the other had severe adhesions after an abdominal trachelectomy.

$65 \%$ of patients $(n=147)$ had previously had one or more mid-trimester losses or neonatal deaths, with a total of 235 babies born before 24 weeks.

Table 1 shows the indication for insertion of laparoscopic cerclage. Of note is the group "Cervical Surgery without pregnancy". Whilst some of these patients had been pregnant in the past, all of these pregnancies were prior to undergoing cervical surgery. All of these patients had undergone extensive oncologic surgery, either trachelectomy, large or multiple cone biopsies and were referred for laparoscopic TAC.

141 pregnancies that have reached 12 weeks have been recorded to date in 126 women (15 women had 2 pregnancies with the same cerclage). 13 women were pregnant at the time of submission for publication. 7 pregnancies were excluded because they ended for reasons not relating to the cerclage. 3 were terminations of pregnancy for early midtrimester diagnosis of congenital abnormalities (trisomy 21 and 18). One baby was delivered by emergency caesarean section at 29.5 weeks for maternal sepsis and abnormal CTG. This baby was subsequently diagnosed with listeria sepsis and died. 2 women had fetal deaths in utero (FDIU) at 21 and 15 weeks respectively. The FDIUs occurred in women with intact membranes and no signs of infection. These cases were excluded when calculating the success rate of the TAC as the cause of fetal loss was not considered attributable to cerclage. The cervix was closed and the cerclage was holding well.

The outcomes of 121 pregnancies ( 125 babies, 5 sets of twins) were analysed for this paper.

Table 2 demonstrates pregnancy outcomes prior to and following laparoscopic TAC insertion in the same women. Of note is the difference in perinatal survival rate and the difference in gestational age in the two groups. In Table 3 gestational age outcomes are broken down by indication for cerclage. There is a significant difference in average gestational age achieved in all groups after TAC insertion.

We recorded two fetal losses which were considered cerclage failures and are shown on Table 4. One patient delivered twins at 24.0 weeks gestation. She ruptured her membranes and went into labour and therefore underwent a caesarean section to deliver the babies. One twin weighing 567grams survived and the second twin weighing 516grams died 5 days after birth. Another patient ruptured her membranes at 15 weeks gestation. A laparoscopy was performed and the cerclage removed. The patient delivered the fetus vaginally. 
17 patients delivered 20 babies (three sets of twins) at between 24 and 34 weeks gestation. 8 of these deliveries occurred due to preterm labour or preterm pre-labour rupture of membranes and their cerclages were deemed suboptimal (average gestational age $29.0+/$ 3.03 weeks). 9 patients had premature deliveries due to other identifiable obstetric causes (average gestational age $31.4+/-2.42$ weeks). We present these cases in tables $5 \mathrm{a}$ and $5 \mathrm{~b}$.

\section{Discussion}

To the best of our knowledge this is the largest case series of pregnancies after laparoscopic transabdominal cerclage. There was a $98.5 \%$ perinatal survival rate with mean gestational age at delivery of $35.2+/-5.57$ weeks. $79.7 \%$ of patients delivered their babies at $\geq 34$ weeks gestation. These figures show a marked improvement in obstetric outcomes in a population with poor past obstetric history due to cervical insufficiency.

\section{Failed transvaginal cerclage}

29\% ( $\mathrm{n}=66$ ) of our patients had a previous failed TVC. 32 have fallen pregnant after the TAC. The live birth rate was $100 \%$ and the average gestational age at delivery was 37.4 weeks

A transabdominal cerclage is often the last resort for women who experience a midtrimester loss with a transvaginal cerclage. In one study of 100 women with failed TVC, of the 55 who conceived and the pregnancy lasted past the first trimester the live birth rate was $96.4 \%{ }^{14}$.

\section{Previous cervical surgery}

90 women were referred because of previous cervical surgery. $72 \%$ had already experienced a pregnancy loss. $28 \%$ were referred before falling pregnant. In 51 pregnancies after the TAC, fetal survival was $99 \%$ and average gestational age 35.4 weeks.

Women who have a trachelectomy are usually not suitable for a TVC. The two options left are conservative management and/or progesterone or a TAC. In a literature review of pregnancy outcomes, Jolley et $\mathrm{al}^{15}$ reported a $10 \%$ incidence of midtrimester loss and $25 \%$ preterm labour. Most successful pregnancies had a transabdominal cerclage, which some authors recommend is inserted at the time of the trachelectomy ${ }^{16}$. This procedure, however, has significant potential complications, the main ones reported being erosion through the vagina and cervical stenosis. Given the low morbidity of the laparoscopic procedure, we recommend to fully treat the cancer and insert the cerclage at a later stage.

$\underline{\text { Previous midtrimester loss }}$

34 women (15\%) chose to have a TAC after one or more midtrimester losses. 17 pregnancies have been completed to date. 16 patients $(94 \%)$ took a baby home. 
A recent study of similar women in Denmark demonstrated a take home baby rate in their second pregnancy of $95 \%$ after abdominal cerclage, $73 \%$ after vaginal cerclage, and 33\% after no cerclage ${ }^{17}$. In an earlier study Sneider et al found the recurrence rate of midtrimester miscarriage with a diagnosis of cervical insufficiency was $28 \%$ with no intervention but lower after vaginal cerclage (OR 0.47) and even lower after abdominal cerclage $(0.14)^{18}$.

\section{Strengths and limitations}

The ideal evidence based methodology to assess the effectiveness of a laparoscopic TAC would be to randomise it against alternative options, such as conservative management and/or transvaginal cerclage. We believe that it would be difficult to conduct such a study. Most of our patients, if not all, had a TAC either because they had already failed a TVC or had a very short cervix not amenable to one. Randomisation to expectant management would not be realistic and, possibly, unethical.

Randomisation of patients amenable to a TVC, to the same or a laparoscopic TAC could be feasible, but it would mean doing a more invasive procedure and committing to a caesarean section some patients who could potentially do well with a TVC. Whilst we acknowledge this as the main limitation of our study, we believe that prospectively evaluating obstetric outcomes in all the women in the group who underwent a TAC is currently the best information we can provide.

All the operations were performed by the same surgeon. This provides consistency of surgical technique and expertise. However, we are not able to assess the outcomes of the procedure by multiple surgeons or institutions. In addition, we have not compared the use of different types of suture, such as the Mersilene tape used by other surgeons.

Some of our patients did not have a history of failed TVC or extensive cervical oncologic surgery and did not fit the classical indication for transabdominal cerclage. The TAC was performed when requested by the patient and deemed appropriate by her treating physicians.

As with any surgical procedure, the aim is to make sure that the benefits outweigh the risks and surgical trauma. The high success of the transabdominal cerclage, not only in terms of neonatal survival, but also increase of gestational age at delivery, reduction in the need for hospital admission and bed rest during the pregnancy as well as reduction in the number of babies admitted to neonatal ICU is remarkable, and supported by a recently published systematic review. ${ }^{19}$

Our main concern in patients with TAC is a midtrimester loss or the need for a midtrimester interruption of the pregnancy. These cases may require a classical hysterotomy, a procedure 
that carries significant morbidity. However when necessary, we were able to remove the suture laparoscopically, allow for a vaginal delivery and redo the cerclage at a later date ${ }^{20}$.

Implications of findings for practice, research and policy

The successful outcomes following laparoscopic TAC should be noted and thus patients who fail a TVC should be counselled appropriately. It is also important that surgeons receive adequate training to learn to perform this procedure.

As with any complex procedure, there is a learning curve and a minimum case load in order to maintain expertise. Each institution should evaluate their needs and train the appropriate number of surgeons.

In order to improve patient selection, outcomes and experience we have created a Cervical Insufficiency multidisciplinary team at the hospital comprised of specialists in maternal fetal medicine, preterm labour, recurrent miscarriage and advanced laparoscopic surgery. A consensus recommendation is provided for all potential candidates for a TAC.

\section{$\underline{\text { Research }}$}

Further research comparing laparoscopic TAC and TVC needs to be done. Of note points of technique within laparoscopic TAC need to be reviewed- for example the best suture material, with a recent trial started comparing mersilene tape with a monofilament nonbraided suture (Ethilon) ${ }^{21}$. Another study of relevance would be that of patient experience- this will help guide both gynaecologists and obstetricians who manage patients with poor obstetric histories.

\section{Conclusion}

This study provides evidence of the effectiveness and feasibility of laparoscopic TAC. It is a useful guide for clinicians when discussing the options with patients. It is also of benefit for laparoscopic surgeons to assess their role in the prevention of preterm labour. Laparoscopic TAC is safe, effective and results in favourable obstetric outcomes for carefully selected women with complex obstetric histories of recurrent midtrimester losses, previous failed TVC and/or previous extensive cervical surgery.

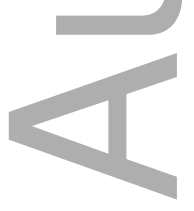

\section{Acknowledgements}

Dr Kim Dobromilsky, Dr James May, Dr Phoebe Hong 


\section{Disclosure of interests}

No conflicts of interest

\section{Contribution to authorship}

Dr Alex Ades: Primary author involved in conception, planning and carrying out of submitted work. Also involved in writing up and critically revising manuscript. Primary surgeon for all laparoscopic transabdominal cerclage cases.

Dr Sneha Parghi: Author involved in carrying out of data collection, analysis and preparation of manuscript. Surgical assistant and post-operative care for several laparoscopic transabdominal cerclage cases.

Dr Mehrnoosh Aref-Adib: Author involved in data collection and literature review and preparation of the manuscript. Surgical assistant and post-operative care for several laparoscopic transabdominal cerclage cases.

\section{Ethics approval}

Ethics approval was obtained from the Royal Women's Hospital, Melbourne, Research Committee and Royal Women's Hospital, Melbourne, Human Research Ethics Committee.

\section{Funding}

No funding to disclose

\section{References}

1. WHO Preterm birth fact sheet November 2016. [Cited 2017 June 6]. Available from:http://www.who.int/mediacentre/factsheets/fs363/en/

2. Easterday CL, Reid DE. The incompetent cervix in repetitive abortion and premature labor. N Engl J Med 1959;260:687-690.

3. Shennan, A.H. and To, M.S., 2011. Green-top guideline No 60: cervical cerclage. RCOG, London.

4. Secher NJ, McCormack CD, Weber T et al. Cervical occlusion in women with cervical insufficiency: protocol for a randomised, controlled trial with cerclage, with and without cervical occlusion. BJOG: An International Journal of Obstetrics \& Gynaecology 2007 May 1;114(5):649-e6.

5. Owen J, Hankins G, Iams JD et al. Multicenter randomized trial of cerclage for preterm birth prevention in high-risk women with shortened midtrimester cervical length. Am J Obstet Gynecol 2009;201(4):375 e1-8

6. Shirodkar VN. A new method of operative treatment for habitual abortions in the second trimester of pregnancy. Antiseptic 1955;52:299-300. 
7. McDonald IA. Suture of the cervix for inevitable miscarriage. J Obstet Gynaecol Br Emp 1957;64: 346-350.

8. Wood SL, Owen J. Cerclage: Shirodkar, McDonald, and Modifications. Clinical obstetrics and gynecology 2016 Jun 1;59(2):302-10.

9. Lesser, KB, Childers, JM and Surwit, EA “Transabdominal cerclage: a laparoscopic approach." Obstet. Gynecol 1998;91:855-856.

10. Burger N, Einarsson J, Brolmann HAM, et al. "Preconceptional laparoscopic abdominal cerclage: a multicentre cohort study". American Journal of Obstetrics and Gynaecology 2012;207:273.e1-12

11. Ades A, May J, Cade T et al. "Laparoscopic transabdominal cerclage: a 6-year experience”. ANZJOG 2014;54:117-120.

12. Ades A, Dobromilsky KC, Cheung KT, Umstad MP. Transabdominal cervical cerclage: laparoscopy versus laparotomy. Journal of minimally invasive gynecology 2015 Oct $31 ; 22(6): 968-73$.

13. Whittle W, Singh S, Allen, L et al. "Laparoscopic cervico-isthmic cerclage: surgical technique and obstetric outcomes". AJOG 2009;201:364.e1-7

14. Huang X, Ma N, Li TC, Guo Y, Song D, Zhao Y, Xia E. Simplified laparoscopic cervical cerclage after failure of vaginal suture: technique and results of a consecutive series of 100 cases. European Journal of Obstetrics \& Gynecology and Reproductive Biology 2016 Jun 30;201:146-50.

15. Jolley JA, Battista L, Wing DA. Management of pregnancy after radical trachelectomy: case reports and systematic review of the literature. Am J Perinatol. $2007 ; 24: 531-9$.

16. Shepherd JH. Cervical cancer. Best Pract Res Clin Obstet Gynaecol 2012 Jun;26(3):293-309.

17. Sneider, K., Christiansen, O.B., Sundtoft, I.B. et al. Recurrence rates after abdominal and vaginal cerclages in women with cervical insufficiency: a validated cohort study. Archives of gynecology and obstetrics 2017; 295(4), pp.859-866.

18. Sneider, K., Christiansen, O.B., Sundtoft, I.B. et al. Recurrence of second trimester miscarriage and extreme preterm delivery at 16-27 weeks of gestation with a focus on cervical insufficiency and prophylactic cerclage. Acta obstetricia et gynecologica Scandinavica 2016; 95(12), pp.1383-1390. 
19. Moawad, G., Tyan, P., Bracke, T. et al. Systematic review of Transabdominal Cerclage placed via laparoscopy for the prevention of Preterm Birth. Journal of Minimally Invasive Gynecology 2017; http://dx.doi.org/10.1016/j.jmig.2017.07.021

20. Ades A, Dobromilsky K. Laparoscopic removal of abdominal cerclage and vaginal delivery at 21 weeks. CRSLS e2014.;247.

21. Israfil-Bayli, F., Toozs-Hobson, P., Lees, C et al. Cerclage outcome by the type of suture material (COTS): study protocol for a pilot and feasibility randomised controlled trial. Trials 2014; 15(1), p.415.

\section{TABLES}

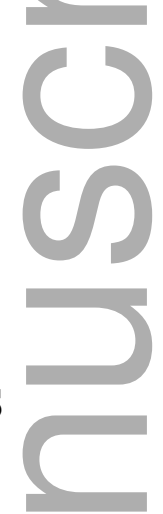

Table 1: Indications

Primary indication Number patients $(\mathrm{N}=225)$

\section{Failed TVC \\ Suboptimal TVC} $66(29.3 \%)$

$32(14.2 \%)$

Cervical surgery and failed TVC $18(8 \%)$

Cervical surgery and suboptimal TVC $16(7.1 \%)$

Cervical surgery and midtrimester loss 
Table 2: Pregnancy outcomes prior to and following laparoscopic TAC insertion.

\begin{tabular}{|c|c|c|}
\hline Outcome & $\begin{array}{l}\text { Pre-Laparoscopic TAC } \\
\qquad(\mathrm{n}=402)\end{array}$ & $\begin{array}{l}\text { Post Laparoscopic TAC } \\
\qquad(\mathrm{n}=121)\end{array}$ \\
\hline Delivery 13-24 weeks & $\mathrm{n}=235(58.5 \%)$ & $\mathrm{n}=2(1.6 \%)$ \\
\hline Delivery $\geq 24.1$ weeks & $\mathrm{n}=167(41.5 \%)$ & $\mathrm{n}=119(98.4 \%)$ \\
\hline Mean gestational age & $23.9+/-9.3$ weeks & $35.17+/-5.57$ weeks \\
\hline \multicolumn{3}{|l|}{ Distribution of GA at delivery } \\
\hline$\leq 24$ weeks & $235(58.5 \%)$ & $2(1.6 \%)$ \\
\hline 24.1-28 weeks & $37(9.2 \%)$ & $4(3.3 \%)$ \\
\hline 28.1-34 weeks & $30(7.5 \%)$ & $11(9.1 \%)$ \\
\hline $34.1-37$ weeks & $20(4.9 \%)$ & $41(33.9 \%)$ \\
\hline$>37.1$ weeks & $80(19.9 \%)$ & $63(52.1 \%)$ \\
\hline Perinatal survival rate & $41.5 \%$ & $98.4 \%$ \\
\hline Delivery after 34 weeks & $24.9 \%$ & $79.7 \%$ \\
\hline Increase in gestational age & - & 11.27 weeks \\
\hline
\end{tabular}

Table 3: Obstetric outcomes pre and post laparoscopic TAC by subgroup

\begin{tabular}{|c|c|c|c|c|c|}
\hline & Pre TAC & & Post TAC & & \\
\hline $\begin{array}{l}\text { Primary } \\
\text { indication }\end{array}$ & $\begin{array}{c}\text { Number } \\
\text { pregnancies } \\
(\mathrm{n}=402)\end{array}$ & $\begin{array}{c}\text { Average } \\
\text { gestational age } \\
\text { (weeks) }\end{array}$ & $\begin{array}{c}\text { Number } \\
\text { pregnancies } \\
(\mathrm{n}=121)\end{array}$ & $\begin{array}{c}\text { Average } \\
\text { gestational } \\
\text { age (weeks) }\end{array}$ & $\begin{array}{c}\text { p-value } \\
\text { (gestational } \\
\text { age) }\end{array}$ \\
\hline Failed TVC & 149 & $22.5+/-3.96$ & 32 & $37.4+/-0.73$ & $p<0.05$ \\
\hline Suboptimal TVC & 58 & $27.7+/-5.39$ & 21 & $35.8+/-3.49$ & $p<0.05$ \\
\hline $\begin{array}{l}\text { Cervical surgery } \\
\text { and failed TVC }\end{array}$ & 45 & $21.7+/-4.79$ & 16 & $34.9+/-5.06$ & $p<0.05$ \\
\hline $\begin{array}{l}\text { Cervical surgery } \\
\text { and suboptimal } \\
\text { TVC }\end{array}$ & 29 & $31.3+/-5.36$ & 5 & $34.6+/-0.94$ & $\mathrm{p}=0.04$ \\
\hline $\begin{array}{l}\text { Cervical surgery } \\
\text { and midtrimester }\end{array}$ & 31 & $23.2+/-5.02$ & 16 & $36.2+/-3.49$ & $p<0.05$ \\
\hline loss (no previous & & & & & \\
\hline
\end{tabular}




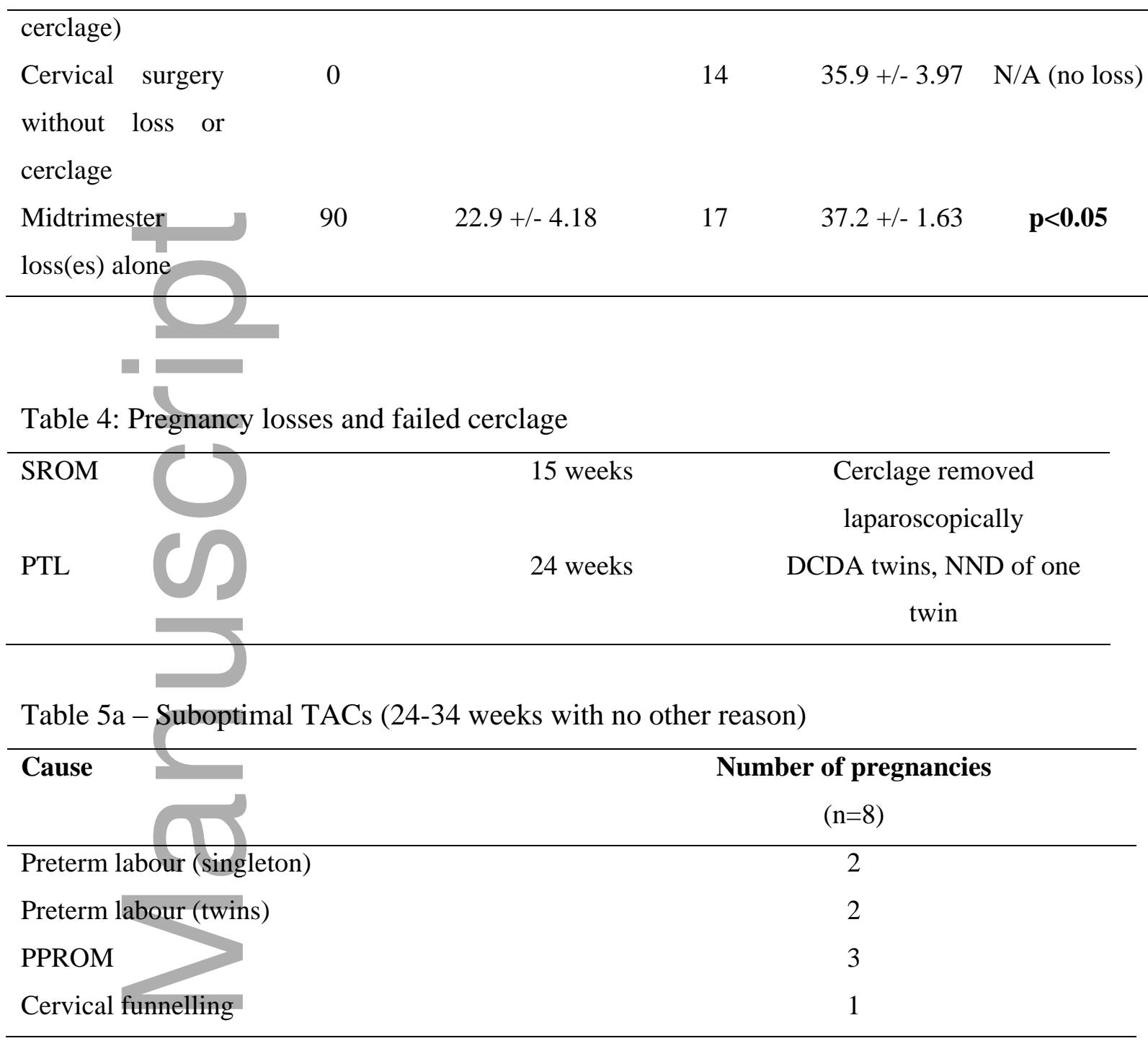

Table $5 \mathrm{~b}$ - Suboptimal TACs due to other Obstetric complications

\begin{tabular}{lc}
\hline Cause & $\begin{array}{c}\text { Number of pregnancies } \\
(\mathrm{n}=9)\end{array}$ \\
\hline Placenta previa & 3 \\
IUGR, preeclampsia & 2 \\
Fetal distress/abnormal CTG & 2 \\
Placental Abruption & 1 \\
Planned & 1 \\
\hline
\end{tabular}


Table 4: Complications

\begin{tabular}{lll}
\hline Uterine perforation & 1 & Sutured laparoscopically \\
Bladder injury & 2 & Sutured laparoscopically \\
& & \\
\hline
\end{tabular}

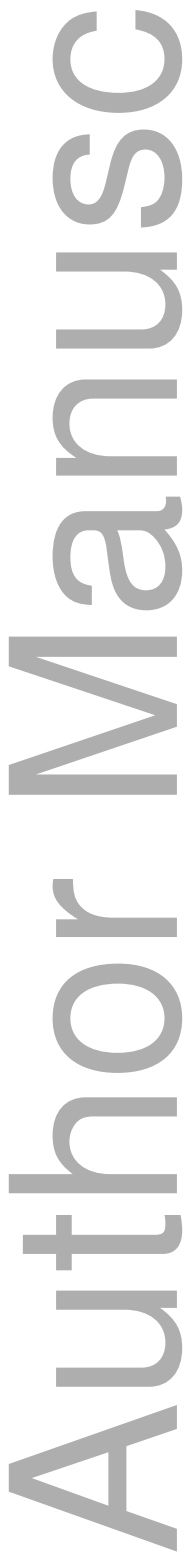

This article is protected by copyright. All rights reserved 


\section{TABLES}

Table 1: Indications

Primary indication Number patients $(\mathrm{N}=225)$

Failed TVC

$66(29.3 \%)$

Suboptimal TVC

$32(14.2 \%)$

Cervical surgery and failed TVC

$18(8 \%)$

Cervical surgery and suboptimal TVC

$16(7.1 \%)$

Cervical surgery and midtrimester loss

$33(14.7 \%)$

Cervical surgery without loss or cerclage

$23(10.2 \%)$

Midtrimester loss(es) no TVC

$34(15.1 \%)$

Preterm birth alone (>/= 24 weeks with surviving baby)

$31.3 \%)$

Table 2: Pregnancy outcomes prior to and following laparoscopic TAC insertion.

\begin{tabular}{lcc}
\hline Outcome & $\begin{array}{c}\text { Pre-Laparoscopic TAC } \\
(\mathrm{n}=402)\end{array}$ & $\begin{array}{c}\text { Post Laparoscopic TAC } \\
(\mathrm{n}=121)\end{array}$ \\
\hline $\begin{array}{l}\text { Delivery 13-24 weeks } \\
\text { Delivery } \geq 24.1 \text { weeks }\end{array}$ & $\mathrm{n}=235(58.5 \%)$ & $\mathrm{n}=2(1.6 \%)$ \\
$\mathrm{n}=167(41.5 \%)$ & $319(98.4 \%)$ \\
Mean gestational age & $23.9+/-9.3$ weeks & $35.17+/-5.57$ weeks \\
Distribution of GA at delivery & & \\
$24.1-28$ weeks & $37(9.2 \%)$ & $4(1.6 \%)$ \\
$28.1-34$ weeks & $30(7.5 \%)$ & $11(9.1 \%)$ \\
$34.1-37$ weeks & $20(4.9 \%)$ & $41(33.9 \%)$ \\
$>37.1$ weeks & $80(19.9 \%)$ & $63(52.1 \%)$ \\
Perinatal survival rate & $41.5 \%$ & $98.4 \%$
\end{tabular}

This article is protected by copyright. All rights reserved 


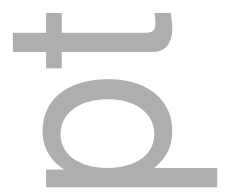

Table 3: Obstetric outcomes pre and post laparoscopic TAC by subgroup

\begin{tabular}{|c|c|c|c|c|c|}
\hline 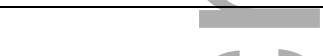 & Pre TAC & & Post TAC & & \\
\hline $\begin{array}{l}\text { Primary } \\
\text { indication }\end{array}$ & $\begin{array}{c}\text { Number } \\
\text { pregnancies } \\
(\mathrm{n}=402)\end{array}$ & $\begin{array}{c}\text { Average } \\
\text { gestational age } \\
\text { (weeks) }\end{array}$ & $\begin{array}{c}\text { Number } \\
\text { pregnancies } \\
(\mathrm{n}=121)\end{array}$ & $\begin{array}{c}\text { Average } \\
\text { gestational } \\
\text { age (weeks) }\end{array}$ & $\begin{array}{c}\text { p-value } \\
\text { (gestational } \\
\text { age) }\end{array}$ \\
\hline Failed TVC & 149 & $22.5+/-3.96$ & 32 & $37.4+/-0.73$ & $p<0.05$ \\
\hline Suboptimal T & 58 & $27.7+/-5.39$ & 21 & $35.8+/-3.49$ & $p<0.05$ \\
\hline $\begin{array}{l}\text { Cervical surgery } \\
\text { and failed TVC }\end{array}$ & 45 & $21.7+/-4.79$ & 16 & $34.9+/-5.06$ & $p<0.05$ \\
\hline $\begin{array}{l}\text { Cervical surgery } \\
\text { and suboptimal } \\
\text { TVC }\end{array}$ & 29 & $31.3+/-5.36$ & 5 & $34.6+/-0.94$ & $\mathrm{p}=0.04$ \\
\hline $\begin{array}{l}\text { Cervical surgery } \\
\text { and midtrimester } \\
\text { loss (no previous } \\
\text { cerclage) }\end{array}$ & 31 & $23.2+/-5.02$ & 16 & $36.2+/-3.49$ & $p<0.05$ \\
\hline $\begin{array}{l}\text { Cervical surgery } \\
\text { without loss or } \\
\text { cerclage }\end{array}$ & 0 & & 14 & $35.9+/-3.97$ & N/A (no loss) \\
\hline $\begin{array}{l}\text { Midtrimester } \\
\text { loss(es) alone }\end{array}$ & 90 & $22.9+/-4.18$ & 17 & $37.2+/-1.63$ & $p<0.05$ \\
\hline
\end{tabular}

Table 4: Pregnancy losses and failed cerclage

\begin{tabular}{lcc}
\hline SROM & 15 weeks & Cerclage removed \\
& & laparoscopically \\
PTL & 24 weeks & DCDA twins, NND of one \\
& & twin \\
\hline
\end{tabular}


Table 5a-Suboptimal TACs (24-34 weeks with no other reason)

\begin{tabular}{lc}
\hline Cause & $\begin{array}{c}\text { Number of pregnancies } \\
(\mathrm{n}=8)\end{array}$ \\
\hline Preterm labour (singleton) & 2 \\
Preterm labour (twins) & 2 \\
PPROM & 3 \\
Cervical funnelling & 1 \\
\hline
\end{tabular}

Table 5b-Suboptimal TACs due to other Obstetric complications

\begin{tabular}{lc}
\hline Cause & $\begin{array}{c}\text { Number of pregnancies } \\
(\mathrm{n}=9)\end{array}$ \\
\hline Placenta previa & 3 \\
IUGR, preeclampsia & 2 \\
Fetal distress/abnormal CTG & 2 \\
Placental Abruption & 1 \\
Planned & 1 \\
\hline
\end{tabular}




\section{University Library}

\section{- M M N E R VA A gateway to Melbourne's research publications}

Minerva Access is the Institutional Repository of The University of Melbourne

Author/s:

Ades, A;Parghi, S;Aref-Adib, M

Title:

Laparoscopic transabdominal cerclage: Outcomes of 121 pregnancies

Date:

2018-12-01

Citation:

Ades, A., Parghi, S. \& Aref-Adib, M. (2018). Laparoscopic transabdominal cerclage:

Outcomes of 121 pregnancies. AUSTRALIAN \& NEW ZEALAND JOURNAL OF

OBSTETRICS \& GYNAECOLOGY, 58 (6), pp.606-611. https://doi.org/10.1111/ajo. 12774.

Persistent Link:

http://hdl.handle.net/11343/283536 